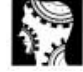

original papers

\section{References}

BENSON, P. R. (1983) Factors associated with antipsychotic drug prescribing by southern psychiatrists. Medical Care 21, 639-654

BHUI, K. (1998) London's Ethnic Minorities and the Provision of Mental Health Services. In London's Mental Health: The Report to the London King's Fund Commission (eds S. Johnson R. Ramsay, G. Thornicroft, et al), pp.143-166. London: King's Fund.

BRITISH MEDICAL ASSOCIATION \& ROYAL PHARMACEUTICAL SOCIETY OF GREAT BRITAIN (1999) British National Formulary. London \& Wallingford: BMJ Books \& Pharmaceutical Press.
CHAPLIN, R. \& McGUIGAN, S. (1996) Antipsychotic dose: from research to clinical practice. Psychiatric Bulletin, 20 452-454

HARRINGTON, M., LELLIOTT, P., PATON, C. et al (2002a) The results of a multicentre audit of the prescribing of antipsychotic drugs for in-patients in the UK. Psychiatric Bulletin, 26, $414-418$

HARRINGTON, M., LELLIOTT, P., PATON, C., et al (2002 b) Variation between services in polypharmacy and high dose of antipsychotic drugs prescribed for in-patients. Psychiatric Bulletin, 26 $418-420$
MUSCETTOLA, G., BOLLINI, P. \& PAMPALLONA, S. (1991) Pattern of neuroleptic drug use in Italian Mental Health Services. Annals of Pharmacotherapy, 25, 296-301.

TIBALDI, G., MUIZZA, C., BOLLINI, P., et al (1997) Utilization of neuroleptic drugs in Italian Mental Health Services: A survey in Piedmont. Psychiatric Services, 48, 213-217.

WALKUP, J.T., MCALPINE, M. A. OLFSON, M., et al (2000) Patients with schizophrenia at risk for excessive antipsychotic dosing. Journal of Clinical Psychiatry, 61, 344-348.

WILKIE, A., PRESTON, N. \& WESBY, R. (2001) High dose neuroleptics - who gives them and why? Psychiatric Bulletin, 25, 179-183.

WORLD HEALTHORGANIZATION (1992) The ICD-10 Classification of Menta and Behavioural Disorders. Clinical Description and Diagnostic Guidelines. Geneva:WHO.
*Paul Lelliott Director, Royal College of Psychiatrists' Research Unit, 83 Victoria Street, London SW1H OHW, Carol Paton Chief Pharmacist, Oxleas NHS Trust, Maria Harrington Multi-Centre Clinical Audit Programme Manager, Royal College of Psychiatrists' Research Unit, Maria Konsolaki Statistician, Royal College of Psychiatrists' Research Unit, Tom Sensky Reader in Psychological Medicine, Imperial College School of Medicine, Chike Okocha Consultant Psychiatrist and Senior Lecturer in Psychiatry, Queen Elizabeth Hospital

Psychiatric Bulletin (2002), 26, 414-418

M. HARRINGTON, P. LELLIOTT, C. PATON, C. OKOCHA, R. DUFFETT AND T. SENSKY

\title{
The results of a multi-centre audit of the prescribing of antipsychotic drugs for in-patients in the UK
}

\author{
AIMS AND METHOD \\ Forty-seven UK mental health \\ services participated in a 1-day audit \\ of prescribing of antipsychotic drugs. \\ Audit standards were derived from \\ national guidelines and consensus \\ statements. \\ RESULTS \\ Of the 3132 patients, $20 \%$ were \\ prescribed a total dose of
}

\author{
antipsychotic medication above that \\ recommended by the British National \\ Formulary. The majority of case notes \\ failed to record an indication for \\ high-dose prescribing or that the \\ patient had been informed; only \\ $8 \%$ had undergone an electro- \\ cardiogram. Forty-eight per cent of \\ patients were prescribed more than \\ one antipsychotic drug.
}

\author{
CLINICAL IMPLICATIONS \\ Antipsychotic prescribing for \\ in-patients often runs counter to \\ existing guideline recommendations. \\ It is likely that many patients who are \\ prescribed high doses or poly- \\ pharmacy are unaware that their \\ prescription is out of line with \\ guideline recommendations and is \\ inadequately monitored.
}

In the UK, 23 antipsychotic drugs are available on prescription, many by more than one route. Most sideeffects of these drugs are dose related, cause substantial morbidity and may contribute to poor treatment adherence (American Psychiatric Association, 1997). It remains unclear whether the risk of sudden death, acknowledged to occur with antipsychotic drugs, is dose related (Royal College of Psychiatrists, 1997). Existing research offers limited guidance on optimal prescribing in individual circumstances. However, reviews have concluded that, in general, the use of high doses or of polypharmacy (simultaneous use of more than one antipsychotic drug) offers little, if any, benefit over moderate doses of a single drug, in relation to the disadvantages (Royal College of Psychiatrists, 1993). This evidence has influenced the development of national guidelines and consensus statements.

\section{Method}

$\dagger$ See editorial pp. 401-402, and pp. 411-414 and pp. $418-420$ this issue.

\section{Development of the audit standards}

Five English-speaking countries have published national guidelines or consensus statements that refer to the prescribing of antipsychotic drugs (American Psychiatric Association, 1997; EPPIC Statewide Services, 1999; New Zealand Ministry of Health, 1996; Royal College of Psychiatrists, 1993, 1997; Working Group for the Canadian Psychiatric Association and the Canadian Alliance for Research on Schizophrenia, 1998). All advise against the use of high doses other than in exceptional circumstances. Four make a similar, explicit recommendation in respect of polypharmacy. Audit standards were derived from these documents and were presented to, and agreed by, a separate 'expert panel' of psychiatric pharmacists and psychopharmacologists. The standards audited, and the measures used to audit them, are shown in Table 1.

\section{Dose}

The British National Formulary (BNF; British Medical Association \& Royal Pharmaceutical Society of Great Britain, 1999) states a maximum recommended dose, or a dose range for all antipsychotic drugs except trifluoperazine. The Royal College of Psychiatrists' consensus statement (Royal College of Psychiatrists, 1993) recommends that, when an antipsychotic is given at a dose above the 
BNF limit the decision should be made by a fully trained psychiatrist; the patient should be informed and his/her consent obtained; an electrocardiogram (ECG) should be performed; regular pulse, blood pressure and temperature checks should be made; and fluid intake should be monitored. A trial of a high-dose prescription should not last longer than 3 months. If there has been no improvement, the dose should be reduced back to within the standard range.

\section{Polypharmacy}

The BNF advises against polypharmacy. However, the College consensus statement suggests that there are some occasions when it is appropriate to give more than one antipsychotic drug concurrently for short periods. These include when changing gradually from one drug to another and when giving a more sedative and/or injectable antipsychotic drug to someone who is very agitated and who is already prescribed another antipsychotic drug on a regular basis.

\section{High dose caused by polypharmacy}

The College consensus statement clearly states that high-dose prescribing may occur because of the additive effects of two antipsychotic drugs that are prescribed concurrently. There are two methods of calculating whether the 'total dose of antipsychotic drug' exceeds the recommended level. One is to convert the doses of the drugs into 'chlorpromazine equivalents' and add these. The other approach, which was used in this audit, is to convert the prescribed dose to its percentage of the upper recommended dose (or maximum dose) for each drug and then to add the percentages (Yorston \& Pinney, 2000). When the sum exceeds 100 , the patient is considered to be receiving a high dose.

For the purpose of the audit, the maximum daily dose for trifluoperazine was taken to be $50 \mathrm{mg}$.

\section{Recruitment of sites}

In February 1998, all UK adult mental health services were invited to take part in the audit; 47 did so. Services from every part of the country and from every main sociodemographic group (inner city, urban, mixed and rural) participated. They included one private hospital and one high security hospital. A total of 241 psychiatric wards (154 acute admission, 69 rehabilitation and 18 forensic) were involved. All wards were primarily for the treatment of people aged $18-65$.

\section{The audit}

Local staff used a pro forma to collect information about all in-patients who were prescribed antipsychotic medication on 5 October 1998. This included details of all prescriptions for antipsychotic medication (drug, daily dose and route of administration). For each prescription, it was noted whether the drug was to be administered routinely or whether it was to be given 'as required' at the discretion of nursing staff. Frequency of administration was recorded for antipsychotic drugs prescribed as depot injections and, for zuclopenthixol acetate, the dose prescribed in the previous 72 hours.

Data collectors used a checklist to collate information from case files for comparison of practice with the standards set out in Table 1.

\section{Data collection and management}

Staff from each site attended a workshop at which the audit standards and methods for data collection were presented and discussed. Completed forms were returned to the Royal College of Psychiatrists' Research Unit where the data were analysed using SPSS for Windows, version 8 .

\section{Results}

Returns gave information about prescribing practice relating to 3132 in-patients.

\section{Frequency of prescribing of high doses and polypharmacy}

Antipsychotic medication at a total dose above the BNF recommended daily limit was prescribed to 613 patients (20\%). For only a small minority of cases ( $n=34 ; 5.5 \%$ of those prescribed a high dose) was this due to the prescription of a single type of antipsychotic drug at a high dose. For the remainder, high-dose prescribing was due to a combination of two or more types of antipsychotic drug. If only antipsychotic drugs prescribed for routine administration were considered, 318 patients (10\% of the total sample) were prescribed a high dose. In all, 1487 patients (48\%) were prescribed more than one antipsychotic drug on the census day. The results of the audit are summarised in Table 1 .

\section{Discussion}

As there was no random selection of the participating services, the cohort may not be fully representative. However, units from all parts of the country took part and the sample is large, containing perhaps $15-20 \%$ of all people in a psychiatric hospital on the census day. This estimate is extrapolated from the bed numbers for England (Department of Health, 1998).

\section{Why are high-dose prescribing and polypharmacy so common?}

The finding that patients in hospital are commonly prescribed high doses is consistent with six smaller scale audits or surveys of psychiatric in-patients carried out in the UK over the past decade (Chaplin \& McGuigan, 1996; Krazucki \& McFarlane, 1996; Milton et al, 1998; Newton et al, 1997; Warner et al, 1995; Yorston \& Pinney, 1997). These studies involved 1084 patients prescribed antipsychotic medication, $32 \%(n=344)$ of whom were prescribed a high dose. original papers 
Table 1. Audited standards and the findings

original

papers

\begin{tabular}{|c|c|c|c|c|c|}
\hline Standard & $\begin{array}{l}\text { Cases } \\
n(\%) \\
\text { Eligible }\end{array}$ & Missing & Included & Audited measure & $\begin{array}{l}\text { Cases } \\
\text { meeting } \\
\text { standarc } \\
n(\%)\end{array}$ \\
\hline \multicolumn{6}{|l|}{ High-dose prescribing } \\
\hline $\begin{array}{l}\text { If a patient is prescribed a trial of high-dose } \\
\text { antipsychotics, the clinical indications should } \\
\text { be documented in the patient's notes }\end{array}$ & 613 & $112(18)$ & $501(82)$ & Clear statement of indications & $212(42)$ \\
\hline $\begin{array}{l}\text { The decision to commence a patient on a high } \\
\text { dose of antipsychotic medication is the } \\
\text { responsibility of the patient's consultant. A } \\
\text { decision to start an elective trial of high-dose } \\
\text { antipsychotic medication must be made by } \\
\text { the patient's consultant or by a deputy who } \\
\text { is on the specialist register }\end{array}$ & 613 & $112(18)$ & $501(82)$ & $\begin{array}{l}\text { Decision recorded to prescribe } \\
\text { above recommended dose } \\
\text { Where decision was recorded, } \\
\text { decision made by consultant }\end{array}$ & $\begin{array}{l}163(33) \\
153(94)\end{array}$ \\
\hline $\begin{array}{l}\text { Patients should be informed that they } \\
\text { are receiving a trial of a high dose of } \\
\text { antipsychotics (or an explanation of why } \\
\text { they were not informed should be } \\
\text { documented) }\end{array}$ & 613 & $112(18)$ & $501(82)$ & $\begin{array}{l}\text { Records show that patient was } \\
\text { informed } \\
\text { Explicit statement why patient } \\
\text { has not been informed }\end{array}$ & $\begin{array}{l}90(18) \\
15(3)\end{array}$ \\
\hline $\begin{array}{l}\text { An electrocardiogram (ECG) to exclude } \\
\text { significant cardiac disease or prolonged } \\
\text { QT intervals should be performed prior } \\
\text { to commencing patients on high-dose } \\
\text { antipsychotics (or an explanation for not } \\
\text { doing so should be documented) }\end{array}$ & 613 & $112(18)$ & $501(82)$ & $\begin{array}{l}\text { Evidence from records that ECG } \\
\text { performed } \\
\text { Statement in notes that ECG } \\
\text { could not be performed }\end{array}$ & $\begin{array}{l}40(8) \\
10(2)\end{array}$ \\
\hline $\begin{array}{l}\text { If a patient is prescribed high-dose } \\
\text { antipsychotic drugs for } 3 \text { months, the } \\
\text { outcome by the end of this time should } \\
\text { be documented in the patient's notes }\end{array}$ & & & 214 & $\begin{array}{l}\text { Clear statement of outcome } \\
\text { Records show outcome reviewed } \\
\text { in the light of the original } \\
\text { indications }\end{array}$ & $\begin{array}{l}147(69) \\
95(44)\end{array}$ \\
\hline \multicolumn{6}{|l|}{ Polypharmacy } \\
\hline $\begin{array}{l}\text { Two or more antipsychotic drugs should only } \\
\text { be given concurrently as part of a considered } \\
\text { treatment plan. Indications include: (a) when } \\
\text { a single antipsychotic has failed to control } \\
\text { symptoms; (b) while switching a patient } \\
\text { between different antipsychotics; } \\
\text { (c) covering a period of acute exacerbation }\end{array}$ & 1487 & $101(7)$ & $1386(93)$ & $\begin{array}{l}\text { Patients fulfilling criterion (a) } \\
\text { Patients fulfilling criterion (b) } \\
\text { Patients fulfilling criterion (c) } \\
\text { Patients meeting none of the } \\
\text { criteria }\end{array}$ & $\begin{array}{l}826(60) \\
290(21) \\
411(30) \\
311(22)\end{array}$ \\
\hline
\end{tabular}

A number of factors need to be considered when interpreting the findings from the multi-centre audit, they are as follows.

\section{The sample is cross-sectional}

This means that it will contain a higher proportion of patients with longer lengths of stay, and probably higher levels of disturbance and disability, than a cohort of consecutive admissions. Also, the audit gives no indication of longitudinal patterns of prescribing. The potential impact of this is illustrated by the finding that $12 \%$ of patients on more than one antipsychotic were in the process of being switched from one antipsychotic to another.

\section{Ward conditions}

About two-thirds of the patients were on acute admission wards. The rate of admission to these wards has increased considerably over the past 15 years despite a reduction in bed numbers. This has resulted in people who are severely disabled and highly disturbed being concentrated on these wards. Some of the prescribing might therefore reflect the use of antipsychotics to control behaviour, in the context of a disturbed ward environment, rather than the rational treatment of psychotic symptoms. Furthermore, the need to free up beds for new admissions creates pressure to discharge people quickly. This might encourage rapid escalation of doses or the premature addition of a second type of antipsychotic drug. The commonest reason given for the use of polypharmacy was that a single drug had failed to control symptoms. It is not known how often the trial of a single antipsychotic drug had lasted $>6$ weeks, as recommended by a number of national guidelines. 


\section{Medication given at the discretion of nurses}

The decision as to whether medication should be given at levels exceeding those recommended by the BNF had, in effect, been left to nursing staff in about half of cases where a doctor had prescribed a high dose. This was through the writing up of 'as required' medication. The audit neither determined whether this was intentional (see below) nor whether nursing staff were sufficiently trained in psychopharmacology to make such decisions. The writing of 'as required' could also lead to the unintentional and unknowing administration of a high dose (Milton et al, 1998).

\section{Psychiatrists might not be aware that they are prescribing high doses}

For two-thirds of patients to whom it applied, the case notes contained no explicit statement that BNF limits had been exceeded. This might reflect sub-optimal record keeping, a lack of awareness or a combination of both. Nearly $95 \%$ of high-dose prescribing was due to polypharmacy. It is possible this represents a second cause of 'covert' high-dose prescribing wherein clinicians lose sight of total additive dose when they give more than one type of drug at the same time (Tyson et al, 1999).

\section{Prescribers might disagree with the guidelines}

When an audit highlights significant divergence from recommended practice, the 'validity' of the guideline should be reconsidered as well as the behaviour of clinicians. The research base for the guidelines, which informed this audit, is not strong and there might also be questions about the extent to which the research findings can be extrapolated to the real-life clinical situations encountered in modern British psychiatry. Also, the recommendations for maximum doses take no account of patient factors, such as age, gender, ethnicity, body mass, smoking or other medication that might influence response or side-effects. Furthermore, there are apparent inconsistencies between BNF maximum recommended doses and comparisons between drugs based on commonly used tables of equivalence. This is particularly important, given the extent to which highdose prescribing is associated with polypharmacy.

\section{Precautions and consent}

Fewer than $10 \%$ of patients prescribed a high dose had undergone an ECG. There might be a number of explanations for this:

(a) it might reflect the lack of awareness that a high dose has been prescribed

(b) psychiatrists might be unaware both of the importance of such a test and of the College guideline (Henderson et al, 1997)

(c) trainee psychiatrists might not feel proficient in interpreting the results of an ECG (Warner et al, 1996).

A lack of awareness of the psychiatrist that a high dose has been prescribed might also partly explain why as many as $80 \%$ of patients appear not to have been informed, let alone given their consent. Patients have made allegations of negligence involving doses of antipsychotics outside the BNF recommended range (Bradley, 1997). The lack of objective data to support the efficacy of high doses, in conjunction with the lack of informed consent (Brabbins et al, 1996) and failure to conduct simple precautionary tests, are likely to make such allegations difficult to defend against.

Prescribing behaviour has probably changed since the 1998 audit owing to the increased use of atypical antipsychotic drugs. This supports the case for further audits of this type.

\section{Acknowledgements}

The authors thank the 'expert panel' of psychopharmacologists and psychiatric pharmacists who helped draft the standards used in this audit: Professor T. Barnes, Dr J. Cookson, J. Donoghue, Professor M. Lader, Dr L. Pilowsky and D. Taylor. The data were collected by staff from the 47 mental health services that participated in the audit.

\section{Declaration of interest}

C. P. has very occasionally received speaker fees from Eli Lilly and Pfizer. Over the past year she has been involved with research projects funded by Novartis, Eli Lilly and Janssen-Cilag, but has not received any personal income from those projects. T. S. has been paid honoraria by numerous pharmaceutical companies for contributing to educational events. In 2000 he attended a meeting as a participant in an advisory board for Pfizer. The views expressed do not necessarily reflect those of the Royal College of Psychiatrists.

\section{References}

AMERICAN PSYCHIATRIC ASSOCIATION (1997) Practice guidelines for the treatment of patients with schizophrenia. American Journal of Psychiatry, 154, 4 (suppl.).

BRABBINS, C., BUTLER, J. \& BENTALL, R. (1996) Consent to neuroleptic medication for schizophrenia: clinical, ethical and legal issues. British Journal of Psychiatry, 168, 540-544.

BRADLEY, J. J. (1997) Litigation against psychiatrists. Psychiatric Bulletin, 21, 321-322

BRITISH MEDICAL ASSOCIATION \& ROYAL PHARMACEUTICAL SOCIETY OF GREAT BRITAIN (1999) British National Formulary. London \& Wallingford: BMJ Books \& Pharmaceutical Press.

CHAPLIN, R. \& MCGUIGAN, S. (1996) Antipsychotic dose: from research to clinical practice. Psychiatric Bulletin, 20 452-454.

DEPARTMENT OFHEALTH (1998) Health and Personal Social Services Statistics for England, 1997 Edition. London: The Stationery Office.

EPPIC STATEWIDE SERVICES (1999) The Australian Clinical Practice Guidelines for Early Psychosis. Victoria, Australia: EPIIC Statewide Services.
HENDERSON,T., GALLAGHER, D. \& STARK, C. (1997) A survey of the use of the electrocardiogram in psychiatry. Psychiatric Bulletin, 21, 136-138.

KRAZUCKI, C. \& MCFARLANE, F. (1996) Electrocardiograms, high-dose antipsychotic treatment and College guidelines. Psychiatric Bulletin, 20 326-330

MILTON, J., LAWTON, J., SMITH, M. et al (1998) Hidden high-dose antipsychotic prescribing: effects of p.r.n. doses. Psychiatric Bulletin, 22 675-677.

NEWTON, K. L., MURTHY, R \& QURESHI, J. (1997) Antipsychotic statement of the College. Psychiatric Bulletin, 21, 408-410.

NEW ZEALAND MINISTRY OF HEALTH (1996) Guidelines for Prescribing Psychotropic Drugs. New Zealand: Wellington.

ROYAL COLLEGE OF PSYCHIATRISTS (1993) Consensus Statement on the Use of High DoseAntipsychotic Medication. Council Report CR26. London: Royal College of Psychiatrists. prescribing in the light of the consensus 


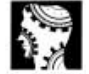

original papers
- (1997) The Association between Antipsychotic Drugs and Sudden Death. Report of theWorking Group of the Royal College of Psychiatrists' Psychopharmacology Sub-Group. Council Report CR57. London: Royal College of Psychiatrists.

TYSON, P. J., MORTIMER, A. M. \& WHEELER, J. A. (1999) High-dose antipsychotic treatment in clinical practice: a review, audit and survey of consultant psychiatrist opinions. Psychiatric Bulletin, 23,661-664.

WARNER, J. P., SLADE, R. \& BARNES, T. R. E. (1995) Change in neuroleptic prescribing practice. Psychiatric Bulletin, 19, 237-239.

-, GLEDHILL, J. A., CONNELL, F., et al (1996) How well do psychiatric trainees interpret electro-cardiographs. A cross-sectional survey. Psychiatric Bulletin, 20,651-652.

WORKING GROUP FOR THE CANADIAN PSYCHIATRIC ASSOCIATION AND THE CANADIAN ALLIANCE FOR RESEARCH ON SCHIZOPHRENIA (1998) Canadian Clinical Practice Guidelines for the Treatment of Schizophrenia. Canadian Journal of Psychiatry, 43(Suppl. 2).
YORSTON, G. \& PINNEY, A. (1997) Use of high dose antipsychotic medication. Psychiatric Bulletin, 21, 566-569.
-\& - (2000) Chlorpromazine equivalents and percentage of British National Formulary maximum recommended dose in patients receiving high-dose antipsychotics. Psychiatric Bulletin, 24, 130-132.
Maria Harrington Multi-Centre Clinical Audit Programme Manager, *Paul Lelliott Director, Royal College of Psychiatrists' Research Unit, 83 Victoria Street, London SW1H OHW, Carol Paton Chief Pharmacist, Oxleas NHS Trust, Chike Okocha Consultant Psychiatrist and Senior Lecturer in Psychiatry, Greenwich District Hospital, Richard Duffett Research Fellow, Royal College of Psychiatrists' Research Unit, London, Tom Sensky Reader in Psychological Medicine, Imperial College School of Medicine

Psychiatric Bulletin (2002), 26, 418-420

\section{HARRINGTON, P. LELLIOTT, C. PATON, M. KONSOLAKI, T. SENSKY AND C. OKOCHA \\ Variation between services in polypharmacy and combined high dose of antipsychotic drugs prescribed for in-patients ${ }^{\dagger}$}

\section{AIMS AND METHOD}

A 1-day census provided an opportunity to examine the variation between 44 mental health services in the frequency of prescribing high doses and polypharmacy of antipsychotic drugs to in-patients on acute psychiatric wards.

\section{RESULTS}

The proportion of patients prescribed a high dose ranged $0-50 \%$ and simultaneous use of more than one antipsychotic drug ranged $12-$ $71 \%$. A number of case-mix variables explained $26 \%$ and $40 \%$, respectively, of the variance between services on these two indicators of prescribing practice.

\begin{abstract}
CLINICAL IMPLICATIONS
Services with high rates of prescription of high dose or polypharmacy might consider a review of clinical practice and of service-level factors that might affect prescribing.
\end{abstract}

One of the stated aims of the UK Government is 'to reduce unacceptable variations in clinical practice' (Department of Health, 1998). Laudable though this aim is, it begs the questions as to what is an 'acceptable' level of variation and what factors, other than the performance of practitioners, influence variation. The first question becomes easier if the extent of variation can be compared with some standard or norm.

There is a consensus among English-speaking countries in the developed world that high doses or polypharmacy of antipsychotic drugs should be avoided, other than in exceptional circumstances (Harrington et al, 2002, this issue). A 1-day census of prescribing provided an opportunity to describe variation between UK mental health in-patient services and the extent to which this guidance is followed.

\section{Method}

\section{Data collection and the sample}

The database used for this study was that described in the accompanying paper (Lelliott et al, 2002, this issue), involving a 1-day census of drugs prescribed to inpatients on psychiatric wards of 49 mental health services. Patients on forensic or rehabilitation wards were not included in this study, reducing the number of mental health services involved to 44 . The 2149 patients on acute psychiatric wards who were prescribed an antipsychotic drug were included. The wards were primarily for people aged 18-64.

\section{Data analysis}

For each patient, prescribed antipsychotic medication was classified as either standard dose or high dose, as defined in the associated paper by Harrington et al (2002, this issue). The unit of analysis was the mental health service. For each service, the percentage of patients in acute wards who were on a high dose of an antipsychotic or polypharmacy was calculated. These percentages were then used as the dependent variable in linear regression analyses to examine how much of the variation between services could be explained by 'case-mix' factors that were known to influence prescribing (Lelliott et al, 2002, this issue). These independent variables were mean age, proportion of patients who were male, proportion detained under the Mental Health Act (MHA) and proportion with a diagnosis of schizophrenic or delusional disorder. Although ethnicity had been found not to influence the probability of being prescribed a high dose or polypharmacy, the proportion 